\title{
Modelling of seakeeping qualities of open-top container carriers in the preliminary design phase
}

\author{
Tomasz Cepowski, Assoc. Prof. \\ Szczecin Maritime University
}

\begin{abstract}

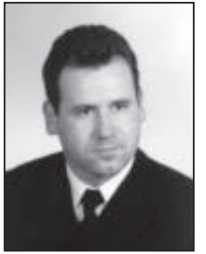

In this paper are presented problems of modelling seakeeping qualities of open-top container carriers in the preliminary design phase. Approximations of accelerations and occurrence rate of green water ingress to holds are presented in function of main ship design and wave parameters. The approximations have been elaborated by applying theory of artificial neural networks in the wide range of ship hull dimensions and forms, while ship motion and wave parameters have been limited to real operational conditions described by means of the so called operational scenario. Such approach has made it possible to reach high accuracy of approximation and simple structure of mathematical model simulatneously.
\end{abstract}

Keywords: open-deck container carrier; designing; preliminary design phase; seakeeping qualities; green water entering the deck; green water ingress to holds; vertical accelerations; transverse accelerations; main ship hull dimensions; artificial neural networks

\section{INTRODUCTION}

In the work [4] a systematization of transport ships has been proposed from the point of view of their seakeeping qualities. In it, a.o. a group of ships having design features which increase their susceptability to weather conditions can be distinguished. To the group can be numbered the ships which usually operate in normal weather conditions however it should be expected that for some time of service they would sail in heavy weather conditions. From the point of view of seakeeping modelling problems the group of ships is characterized by design features which elevate their susceptibility to weather conditions with a view of safety of ship itself or its cargo. To the group can be numbered the following kinds of ships intended for the carrying of solid cargo vertically loaded through deck hatches, and fitted with open main deck which is:

1. either closed by means of hatch covers:

a. universal wide-hatch bulk carriers,

b. general cargo ships,

c. container carriers,

d. con-ro ships,

2. or not closed by means of hatch covers:

a. open-top container carriers,

b. con-ro open-top ships.

Main design problems for the group of ships concern ensuring an appropriate transport capacity as to amount of transported cargo, ship speed and required operational autonomy. In view of specificity of the transported cargo and design features of the ships in question, for them a.o. seakeeping qualities and in particular the necessity of:

- minimization of accelerations which may cause shifting or damaging the cargo and hull structure failure,

- minimization of amount of green water entering the deck which may lead to its ingress to holds constitute technical constraints.

The open-top container carrier represents the group of ships. Specific configuration of holds of open-top container carrier solves many general design problems characteristic for classical containership, such as:

- the problem of ship stability which results from high location of its centre of gravity,

- the problem of arrangement of containers which results from necessity of their arranging on the deck is such a way as to avoid necessity of displacing a number of them to make it possible to remove certain ones out of holds,

- the problem of proper securing containers located on the deck in the highest tiers against dynamic loads due to accelerations which can lead to their losing,

- the problem of proper design of hatch covers which transfer large loads and are to be highly reliable.

However on the other hand, the lack of hatch covers and carrying the containers in one stock generates additional problems: 
- those resulting from large weight of stock of containers:

- double bottom of open-top containerships is to be more strong,

- large mass inertia forces which result from vertical and transverse accelerations may lead to the damaging of containers or hull structure.

- green water entering the deck and its subsequent ingress to holds.

On 26 February 2007 on the open-top containership „Annabella" during its voyage to Helsinki an accident associated with collapsing containers in an open hold, took place [7]. Consequently, 7 containers located in the hold close to ship's plane of symmetry, sufferred damage. As results from the report [7] the formal cause of the event was an inappropriate arrangement of containers. However its physical cause was an incorrect value of initial metacentric height that led to accelerations whose resultants generated large mass inertia forces.

Another formal problem associated with lack of hatch covers was non-fulfilment of the requirements resulting from International Convention on Loadlines, which deal with construction of freeboard deck. Because of the non-fulfilment of the requirements the Maritime Safety Committee adopted, in 1993, additional guidelines dealing with construction of open-top containerships. In particular there were defined the requirements concerning seakeeping model tests, which dealt with a.o. the following, [6]:

- all the model tests are to be performed under the assumption on irregular waves described by the wave spectrum of JONSWAP, Pierson-Moskovitz, or Bretschneider type, with the following parameters: the wave significant height $\mathrm{H}_{\mathrm{S}}=8.5 \mathrm{~m}$ and the most unfavourable characteristic wave frequencies,

- all the model tests are to be performed at least in the following conditions:

- wave encounter angles:

- following wave $\beta=0^{\circ}$,

- head wave $\beta=180^{\circ}$,

- oblique following wave $\beta=45^{\circ} / 315^{\circ}$,

- oblique head wave $\beta=135^{\circ} / 225^{\circ}$,

- beam wave $\beta=90^{\circ} / 270^{\circ}$,

- ship speeds:

- maximum speed on head or oblique head wave,

- minimum speed on following or oblique following wave,

- zero-speed (the so called dead ship condition) on beam wave,

- the model tests should be conducted for the ship in maximum draught load conditions.

Amount of water flooding open-top containership holds depends a.o. on: freeboard height, wave parameters, ship motion parameters, hydromechanic parameters as well as geometrical ship hull parameters such as: underwater hull form and dimensions (ship length in particular), draught, form of aft- and fore- hull parts, deck shape and bulwark structure $[1,3,5,8]$.

\section{DESIGN PARAMETERS WHICH AFFECT SEAKEEPING QUALITIES OF OPEN-TOP CONTAINER CARRIERS}

With a view of the above specified aspects among the crucial seakeeping qualities of open-top container carriers the following can be numbered:

- phenomenon of green water entering the deck, which influences green water ingress to holds,
- transverse and vertical accelerations which may result in generating large mass forces leading to:

- crushing containers placed in the lower part of stocks,

- hull structure damage.

Occurrence of the above mentioned effects of wave action depends a.o. on the main geometric hull parameters of containership, which are modeled in the parametric ship design phase.

Out of the above mentioned parameters the following ones affect phenomenon of green water entering the deck:

- the freeboard height $\mathrm{Fb}$,

- the ship length L,

- the block coefficient of underwater hull part, $\mathrm{CB}$,

- the block coefficient of fore underwater hull part, CBF.

According to $[3,8]$ the above mentioned are crucial for occurrence of phenomenon of green water entering the deck, hence they may also greatly influence green water ingress to holds.

And, as results from [4] the phenomenon of green-water ingress to holds is affected by the following:

- freeboard height,

- middlebody length,

- block coefficients of fore and aft part of underwater hull.

And, vertical and transverse accelerations are affected by the following design parameters:

- the geometric underwater hull parameters:

- the ship length L,

- the ship length/breadth ratio L/B,

- the ship breadth/draught ratio B/d,

- height of ship gravity centre, which influences initial transverse metacentric height and initial longitudinal metacentric height.

As results from [7], the loads generated in lashing system of containers and the event of crushing the containers could be affected by such factors as:

- initial transverse metacentric height,

- unfavourable wave parameters (wave period).

It is not possible today to take into account the above mentioned seakeeping qualities in the parametric design phase as there are no simple, and simultaneously accurate, analytical functions which could make it possible to predict the above mentioned seakeeping qualities on the basis of:

- main geometric parameters of underwater hull,

- parameters which describe load condition,

- parameters of waves occurring in a assumed water area of ship operation.

Formal requirements for the designing of open-top containerships impose the necessity of performing ship model tests aimed at determining amount of water flooding holds without hatch covers.

To perform such tests is not possible in the parametric design phase but only in that design phase when dimensions of ship hull and its general form are already konwn. The model tests of open-top containerships, presented for instance in [1], make only possible to compare given design solutions from the point of view of freeboard height or a form of selected parts of hull. The model tests do not account for the influence of main geometric dimensions of hull as well as wave parameters on occurrence rate of green-water entering the deck.

Formal formulae for calculating vertical and transverse accelerations to determine additional loads exerted to 
containers, given in classification rules, are too general and do not take into account the following:

- influence of the parameters which describe ship loading conditions, such as ship weight or height of its gravity centre,

- influence of wave parameters.

Informal design guidelines are limited first of all to the tests dealing with green water entering the deck of a given ship and do not find any application in the parametric design phase of open-top containership.

\section{AIM AND METHOD OF THE RESEARCH}

In the work [4] have been presented the methods for predicting green water ingress to holds of open-top containership in its initial design phase, based only on hull form parameters and set hull dimensions. And, the research presented in this publication has been aimed at prediction of accelerations and occurrence rate of green water ingress to holds with a view of hull form and dimensions.
It was assumed that the above defined aim can be reached by analyzing results of numerical calculations of ship motions in waves in conventional operational conditions described by operationaal scenarios. The research method scheme is presented in Fig. 1.

To make the above mentioned aim possible an additional aim concerning determination of an essential operational scenario for open-top containership, was formulated.

In approximating maximum significant amplitudes and occurrence rates of the assumed seakeeping qualities the following was taken into account:

- set of explaining variables, which contained:

- hull design parameters,

- wave parameters,

- set of to-be-explained variables, which comprised:

- occurrence rates of green water ingress to holds,

- significant amplitudes of transverse and vertical accelerations occurring in holds.
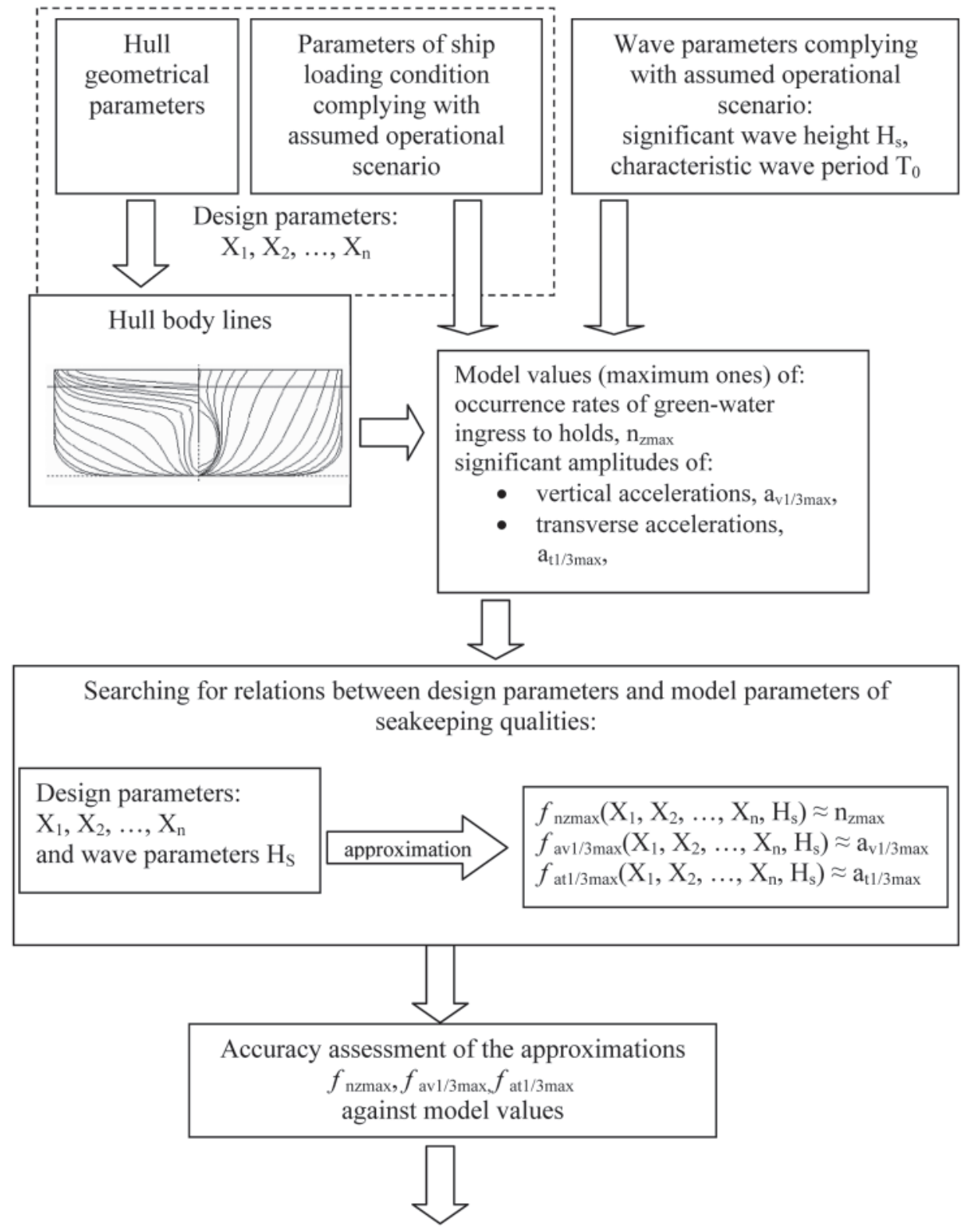

Applicability range of the approximations:

$$
f_{\text {nzmax }}, f_{\text {av } 1 / 3 \max }, f_{\text {at } 1 / 3 \max }
$$

Fig. 1. Algorithm of approximation process of assumed seakeeping qualities in function of design parameters of open-top containerships 
Values of the above specified variables were affected by assumptions resulting from the selected operational scenario.

Wave period greatly influences effects of wave- ship iteraction. Investigations carried out on FPSO ships demonstrated that the assumption of the characteristic wave period value equivalent to the so called 100-year wave, in design calculations, resulted in misfit of main dimensions of such ships to real wave conditions and hazardous escalation of phenomenon of green water entering the deck (Fig. 2).

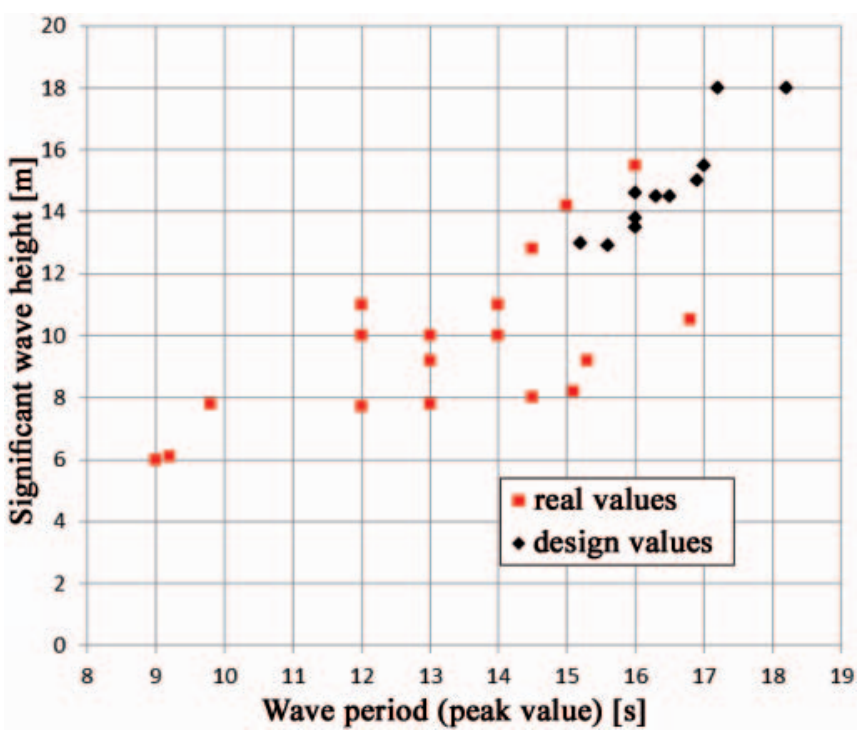

Fig. 2. Values of wave parameters at which hazardous green water entering the deck occurs, obtained for both design and real conditions [2]

Therefore in order to avoid the problem in this research it was decided to approximate maximum values of the assumed seakeeping qualities by taking into account the characteristic wave period. The so elaborated approximations may provide over-estimated values but account for unfavourable influence of wave period on ship motions. An advantage achieved from such solution is elimination of wave period from the set of explaining variables and simplification of the approximation model.

\section{OPERATIONAL SCENARIO}

For modeling seakeeping qualities of open-top containership it was assumed that the ship is intended for operating in the conditions described in [6]. To this end the following operational scenario was assumed:

The open-top containership sails, under its maximum draught, with the speed of $10 \mathrm{~m} / \mathrm{s}$ in stormy weather. In view of necessity of conducting cargo segregation the hold no. 1 is fitted with hatch covers and the remaining ones are without covers. The ship is subjected to action of irregular statistical wave of the parameters complying with [6]. The wave has various characteristic periods and acts from various directions, causing the following:

- maximum occurrence rate of green water ingress to the open-top holds,

- maximum amplitudes of transverse and vertical accelerations acting onto containers placed in stocks in open-top holds.

The above mentioned scenario can be described by the following parameters:

- the ship speed $\mathrm{v}=10 \mathrm{~m} / \mathrm{s}$,

- the wave encounter angle $\beta$ ranging from $0^{\circ}$ to $180^{\circ}$,

- the JONSWAP wave spectrum, the amplification factor $\gamma=3.3$,

- the significant wave height Hs ranging from 1 to $8.5 \mathrm{~m}$,

- the characteristic wave period which causes occurrence of maximum amplitudes of transverse and vertical accelerations.

\section{HULL DESIGN PARAMETERS}

Open-top containerships are relatively small and few in number. Tab. 1 presents the set of main dimensions and their ratios of the representatives of the group of ships in question.

As results from Tab. 1, the design parameters of open-top containerships are contained within the following ranges:

- $\mathrm{L}_{\mathrm{p}} / \mathrm{B}: 5 \div 7.2$,

- B/d: $2.5 \div 4.7$,

- $\mathrm{H} / \mathrm{d}: 1.46 \div 2.11$,

- $\mathrm{L}_{\mathrm{pp}} \mathrm{Bd}: 7182 \div 125346 \mathrm{~m}^{3}$.

For the modelling of seakeeping qualities, were assumed the following ranges of values of hull geometric parameters, covered by the above specified ranges:

- for $\mathrm{L}_{\mathrm{pp}} \mathrm{Bd}: 7000 \div 130000 \mathrm{~m}^{3}$,

- for $\mathrm{L}_{\mathrm{pp}} / \mathrm{B}: 5 \div 8$,

- for $\mathrm{B} / \mathrm{d}: 2.3 \div 4.7$,

- for $\mathrm{H} / \mathrm{d}: 1.3 \div 3.3$,

as well as the underwater hull forms shown in Fig. 3. Their global coefficients are presented in Tab. 2.

On the basis of the above described assumptions the set of 2816 variants of hull forms and dimensions was elaborated. Value of the initial metacentric height GM was assumed, for each of the variants, from the range of $0.4 \div 1.8 \mathrm{~m}$, every $0.2 \mathrm{~m}$.

Tab. 1. Main dimensions and their ratios of representatives of open-top containerships

\begin{tabular}{|c|c|c|c|c|c|c|c|c|}
\hline Name & $\mathrm{L}_{\mathrm{pp}}[\mathrm{m}]$ & $\mathrm{B}[\mathrm{m}]$ & $\mathrm{d}[\mathrm{m}]$ & $\mathrm{H}[\mathrm{m}]$ & $\mathrm{H} / \mathrm{d}$ & $\mathrm{L}_{\mathrm{pp}} / \mathrm{B}$ & $\mathrm{B} / \mathrm{d}$ & $\mathrm{L}_{\mathrm{pp}} \mathrm{Bd}\left[\mathrm{m}^{3}\right]$ \\
\hline $\mathbf{1 7 8}$ type & 155.40 & 26.80 & 9.60 & 14.00 & 1.46 & 5.80 & 2.79 & 39981 \\
\hline $\mathbf{1 6 8}$ type & 124.41 & 22.50 & 8.70 & 14.00 & 1.61 & 5.53 & 2.59 & 243536 \\
\hline $\mathbf{1 6 1}$ type & 136.80 & 25.90 & 9.61 & 14.00 & 1.46 & 5.28 & 2.70 & 34049 \\
\hline Atlantic Lady & 160.00 & 28.80 & 9.00 & 16.80 & 1.87 & 5.56 & 3.20 & 41472 \\
\hline NB1020 Reestborg & 124.40 & 20.00 & 6.30 & 12.60 & 2.00 & 6.22 & 3.17 & 15674 \\
\hline Nedlloyd Hong-Kong & 265.00 & 37.75 & 12.53 & 23.25 & 1.86 & 7.02 & 3.01 & 125346 \\
\hline Norasia Hong-Kong & 229.50 & 32.24 & 11.00 & 23.00 & 2.09 & 7.12 & 2.93 & 81389 \\
\hline Bell Pioneer & 107.18 & 16.92 & 5.93 & 12.52 & 2.11 & 6.33 & 2.85 & 10753 \\
\hline
\end{tabular}


Tab. 2. Assumed variants of underwater hull form described by: $\boldsymbol{C B}$ - underwater hull block coefficent, $\boldsymbol{C B}(\boldsymbol{L})-$ underwater hull cylindrical coefficient, $\boldsymbol{C B}(\boldsymbol{V})$ - underwater hull vertical prismatic coeffcient, $\boldsymbol{C B} \boldsymbol{A}$-underwater hull aft part block coefficient, $\boldsymbol{C B \boldsymbol { F }}$ - underwater hull fore part block coefficient, $\boldsymbol{C W L}$ - waterplane coefficient, $\boldsymbol{C M}$ - midship section coefficient, $\boldsymbol{X} \boldsymbol{F}$ - percentage distance of waterplane geometric centre from aft perpendicular related to ship length between perpendiculars, $\boldsymbol{X} \boldsymbol{B}$ - percentage distance of buoyancy centre from aft perpendicular related to ship length between perpendiculars

\begin{tabular}{|c|c|c|c|c|c|c|c|c|c|}
\hline No. & $\begin{array}{c}\text { CB } \\
{[-]}\end{array}$ & $\begin{array}{c}\text { CB(L) } \\
{[-]}\end{array}$ & $\begin{array}{c}\text { CB(V) } \\
{[-]}\end{array}$ & $\begin{array}{c}\text { CBA } \\
{[-]}\end{array}$ & $\begin{array}{c}\text { CBF } \\
{[-]}\end{array}$ & $\begin{array}{c}\text { CWL } \\
{[-]}\end{array}$ & $\begin{array}{c}\text { CM } \\
{[-]}\end{array}$ & $\begin{array}{c}\text { XF } \\
{[\%]}\end{array}$ & $\begin{array}{c}\text { XB } \\
{[\%]}\end{array}$ \\
\hline $\mathbf{1}$ & 0.58 & 0.59 & 0.78 & 0.60 & 0.55 & 0.73 & 0.97 & 45.82 & 48.49 \\
\hline $\mathbf{2}$ & 0.55 & 0.59 & 0.76 & 0.43 & 0.48 & 0.73 & 0.94 & 44.59 & 46.92 \\
\hline $\mathbf{3}$ & 0.70 & 0.74 & 0.90 & 0.59 & 0.59 & 0.78 & 0.94 & 50.02 & 50.10 \\
\hline $\mathbf{4}$ & 0.58 & 0.61 & 0.85 & 0.53 & 0.46 & 0.68 & 0.97 & 47.81 & 47.94 \\
\hline $\mathbf{5}$ & 0.63 & 0.67 & 0.76 & 0.64 & 0.58 & 0.82 & 0.97 & 40.66 & 45.65 \\
\hline $\mathbf{6}$ & 0.61 & 0.64 & 0.79 & 0.53 & 0.65 & 0.78 & 0.98 & 44.59 & 47.52 \\
\hline $\mathbf{7}$ & 0.57 & 0.60 & 0.81 & 0.58 & 0.55 & 0.71 & 0.98 & 47.35 & 48.12 \\
\hline $\mathbf{8}$ & 0.62 & 0.65 & 0.73 & 0.63 & 0.62 & 0.85 & 0.98 & 41.41 & 48.71 \\
\hline $\mathbf{9}$ & 0.56 & 0.59 & 0.80 & 0.56 & 0.53 & 0.70 & 0.97 & 45.20 & 47.66 \\
\hline $\mathbf{1 0}$ & 0.58 & 0.61 & 0.77 & 0.61 & 0.52 & 0.75 & 0.98 & 43.34 & 46.76 \\
\hline $\mathbf{1 1}$ & 0.54 & 0.58 & 0.80 & 0.55 & 0.45 & 0.67 & 0.93 & 43.51 & 45.99 \\
\hline
\end{tabular}

Variant No.1
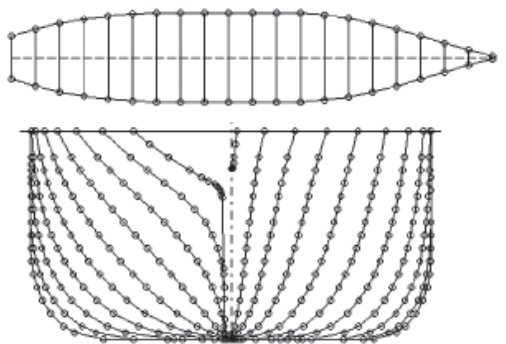

Variant No. 4
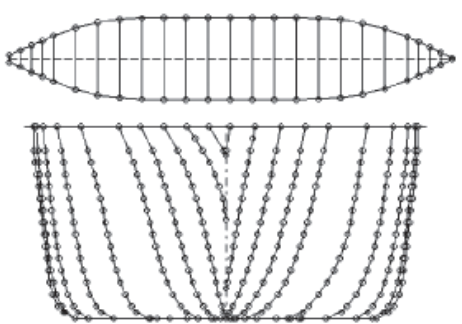

Variant No. 7
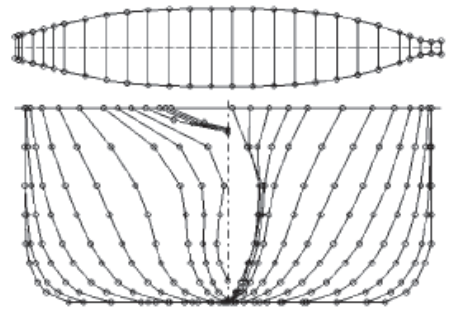

Variant No.2
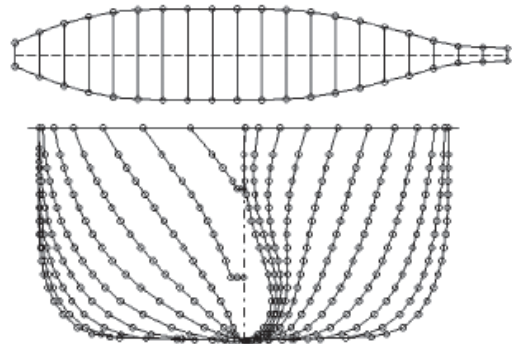

Variant No.5
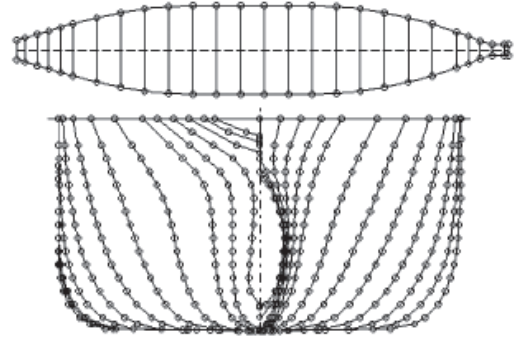

Variant No. 8
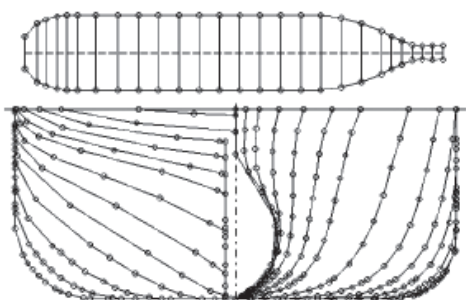

Variant No.3
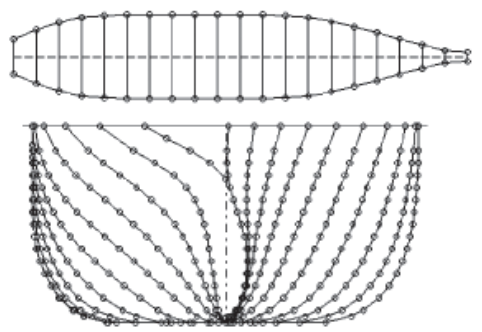

Variant No.6

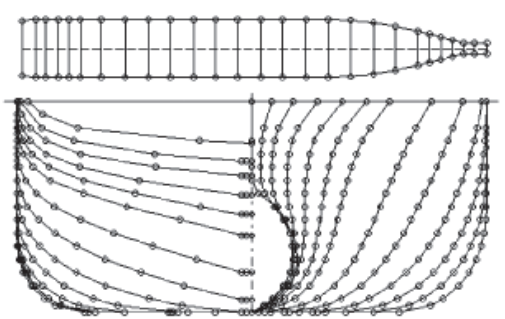

Variant No. 9
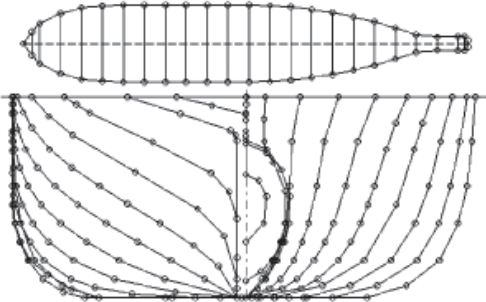

Variant No. 10

Variant No. 11
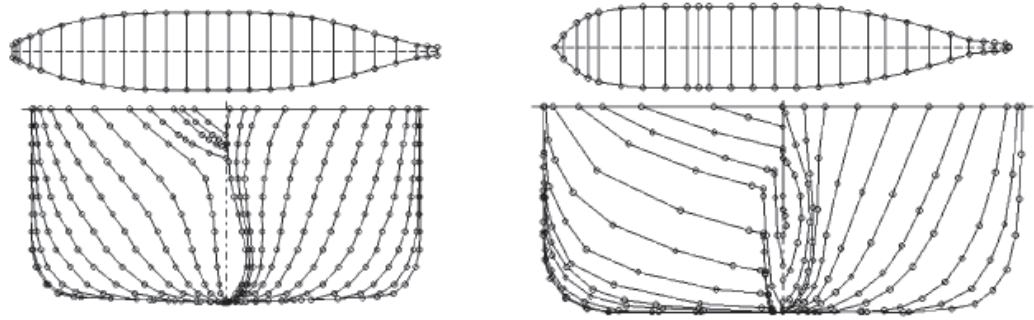

Fig. 3. Assumed variants of underwater hull body lines of containerships 


\section{WAVE PARAMETERS}

For calculations of model values of seakeeping qualities the wave parameters resulting from the assumed operational scenario, were taken as follows:

- the JONSWAP wave spectrum, the amplification factor $\gamma=3.3$;

- the significant wave height $\mathrm{H}_{\mathrm{s}}=4.5 ; 6.5 ; 8.5 \mathrm{~m}$;

- the characteristic wave period $\mathrm{T}_{0}$ in the range from 2 to $20 \mathrm{~s}$, every $0.5 \mathrm{~s}$.

In the operational scenario it was assumed to take into account occurrence of maximum values of seakeeping qualities in function of the characteristic wave period. Therefore to approximate significant amplitudes and occurrence rates of the assumed seakeeping qualities, only the significant wave height $\mathrm{H}_{\mathrm{s}}$ was selected out the all wave parameters, in order to serve as the explaining variable.

\section{MODEL VALUES OF SEAKEEPING QUALITIES}

The following to-be-explained variables were assumed in this research:

- the occurrence rates of green water ingress to holds, $n_{z \max }$ in the point A (acc. Fig. 3),

- the significant amplitudes of transverse accelerations, $\mathrm{a}_{\mathrm{t} 1 / 3 \max }$, and vertical accelerations, $\mathrm{a}_{\mathrm{v} 1 / 3 \max }$, in the point $\mathrm{B}$ of the hold,

In Fig. 4 and Tab. 3 is given location of the points in which the above mentioned seakeeping qualities have been calculated.

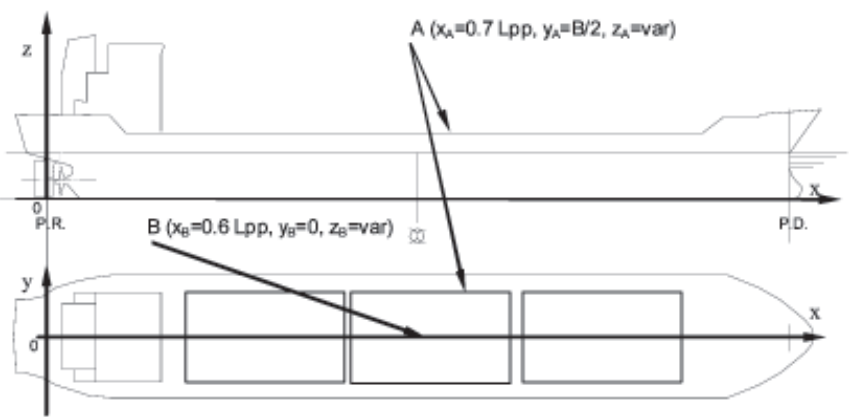

Fig. 4. Location of the points in which the occurrence rate of green wate ingress to holds (the point $\boldsymbol{A}$ ) and transverse and vertical accelerations (the point $\boldsymbol{B})$ were calculated

Tab. 3. Coordinates of the points for which model values of seakeeping qualities were calculated, where: $\boldsymbol{L}_{p p}$ - ship length b.p., $\boldsymbol{B}$ - ship breadth, $\boldsymbol{d}$-ship draught

\begin{tabular}{|c|c|c|c|c|}
\hline $\begin{array}{c}\text { Seakeeping } \\
\text { quality }\end{array}$ & Point & \multicolumn{3}{|c|}{ Coordinates of the point } \\
\hline $\begin{array}{c}\text { Green water } \\
\text { ingress to } \\
\text { holds }\end{array}$ & $\mathrm{A}$ & $\mathrm{x}_{\mathrm{A}}=0.7 \mathrm{~L}_{\mathrm{pp}}$ & $\mathrm{y}_{\mathrm{A}}=\mathrm{B} / 2$ & $\mathrm{z}_{\mathrm{A}}=(1,3 \div 3.3) \mathrm{d}$ \\
\hline $\begin{array}{c}\text { Transverse } \\
\text { and vertical } \\
\text { accelerations }\end{array}$ & $\mathrm{B}$ & $\mathrm{x}_{\mathrm{B}}=0.6 \mathrm{~L}_{\mathrm{pp}}$ & $\mathrm{y}_{\mathrm{B}}=0 \mathrm{~m}$ & $\mathrm{z}_{\mathrm{B}}=(0 \div 2) \mathrm{d}$ \\
\hline
\end{tabular}

Model values of the above mentioned seakeeping qualities were numerically determined by using SEAWAY software in the whole range of wave encounter angles. As resulted from the calculations the most unfavourable wave encounter angles from the point of view of the assumed seakeeping qualities (and accounting for the most unfavourable wave periods) were the following:

- $\beta=120^{\circ}$ for green water ingress to holds,

- $\beta=120^{\circ}$ for transverse accelerations,

- $\beta=90^{\circ}$ for vertical accelerations.

\section{ELABORATION OF APPROXIMATION FUNCTIONS FOR THE ASSUMED \\ SEAKEEPING OUALITIES OF OPEN-TOP CONTAINERSHIPS AND ASSESSMENT OF THEIR ACCURACY}

At first approximations of model values of seakeeping qualities were searched for in the form of analytical functions by using linear regression in the domain of functions of the simplest forms. However it turned out that the elaborated approximations were not suffciently accurate. Just the use of the theory of artificial neural networks brought satsifactory results, that made it possible to elaborate the approximations:

- of maximum occurrence rates of green water ingess to holds:

$$
\mathrm{n}_{\mathrm{z} \max }=\mathrm{H}_{\mathrm{S}} \cdot \frac{\frac{1}{1+\mathrm{e}^{-[(\mathrm{X} \times \mathrm{S}+\mathrm{P}) \times \mathrm{A}-\mathrm{B}]}} \times \mathrm{C}-0.876}{0.0037}
$$

where:

$\mathrm{n}_{\mathrm{zmax}}-$ maximum hourly occurrence rate of green water ingress to holds $[\mathrm{Nr} / \mathrm{h}]$

$\mathrm{H}_{\mathrm{S}} \quad$ - significant wave height $[\mathrm{m}]$,

$\mathrm{X}$ - vector of values of the design parameters:

$$
\mathrm{X}=\left[\mathrm{CBF}, \mathrm{d}, \mathrm{B}, \mathrm{F}_{\mathrm{w}}, \mathrm{CB}, \mathrm{F}_{\mathrm{b}}\right]
$$

where:

CBF - underwater hull fore part block coefficent [-],

d $\quad-$ ship draught [m],

B - ship breadth [m],

CB - underwater hull block coefficent [-],

$\mathrm{F}_{\mathrm{b}} \quad-$ freeboard height $[\mathrm{m}]$,

A - matrix of weighing walues:

$\left[\begin{array}{cccccc}0.012 & -2.686 & -1.775 & -4.621 & -0.362 & -2.327 \\ 3.985 & -1.976 & -0.874 & 3.159 & 1.258 & 0.794 \\ -5.538 & 0.272 & 0.348 & -2.951 & 0.947 & -0.079 \\ -0.307 & -0.295 & -0.512 & -0.575 & 1.197 & -0.450 \\ 0.484 & -0.023 & -0.846 & -7.128 & -0.649 & -2.492 \\ -10.289 & -4.018 & -4.648 & -7.273 & 3.485 & -4.048\end{array}\right]$

S - matrix of coeffcients:

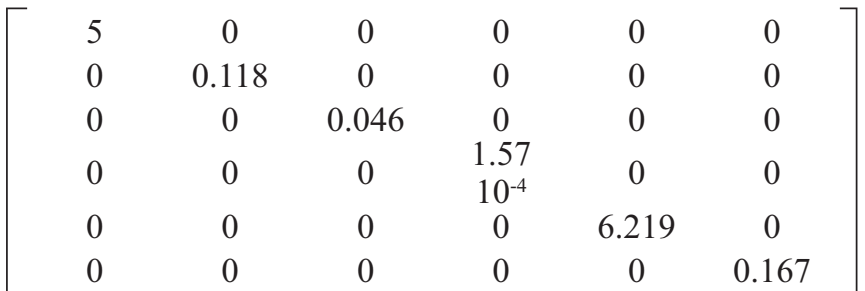

B - vector of thershold values:

$\left[\begin{array}{llllll}3.091 & 0.712 & -0.115 & 1.240 & -2.197 & 0.834\end{array}\right]$

C - column vector of weighing values:

$\left[\begin{array}{llllll}4.715 & -1.716 & 1.412 & 5.511 & 0.879 & -1.277\end{array}\right]$

$\mathrm{P} \quad-$ vector of displacement values:

$\left[\begin{array}{llllll}-2.250 & -0.511 & -0.749 & -0.196 & -3.338 & -0.667\end{array}\right]$ 
- of maximum significant amplitudes of transverse accelerations:

$$
\mathrm{a}_{\mathrm{t} \max }=\mathrm{H}_{\mathrm{S}} \cdot \frac{\frac{1}{1+\mathrm{e}^{-[(\mathrm{X} \times \mathrm{S}+\mathrm{P}) \times \mathrm{A}-\mathrm{B}]}} \times \mathrm{C}+2.667}{0.01723}
$$

where:

$a_{\operatorname{tmax}}-$ maximum significant amplitudes of transverse accelerations $\left[\mathrm{m} / \mathrm{s}^{2}\right]$,

$\mathrm{X}-$ vector of values of the design parameters:

$$
\mathrm{X}=\left[\mathrm{d}, \mathrm{B}, \mathrm{F}_{\mathrm{w}}, \mathrm{XF}, \mathrm{V}, \mathrm{L}_{\mathrm{pp}} / \mathrm{B}, \mathrm{GM}, \mathrm{z} / \mathrm{d}\right]
$$

where:

XF - distance of waterplane geometric centre from aft perpendicular $[\mathrm{m}]$,

$\mathrm{V} \quad-$ volume of underwater hull part $\left[\mathrm{m}^{3}\right]$,

$\mathrm{L}_{\mathrm{pp}} \quad$ - ship length b.p. [m],

$\mathrm{GM}$ - initial transverse metacentric height [m],

$\mathrm{z} \quad-$ height of container gravity centre [m],

d $\quad-$ ship draught $[\mathrm{m}]$,

A - matrix of weighing values:

$\left[\begin{array}{ccccc}1.726 & 0.466 & 1.452 & 1.314 & 0.341 \\ 0.206 & -1.270 & -2.278 & 1.285 & 2.910 \\ 0.317 & -0.830 & -1.312 & 0.895 & 1.734 \\ -0.834 & -0.638 & -0.703 & 0.027 & 1.733 \\ 1.505 & -0.462 & -0.221 & -0.361 & -1.559 \\ 0.325 & 0.746 & 1.012 & -0.203 & -0.762 \\ -1.638 & -1.101 & 2.993 & -1.194 & -2.260 \\ -0.843 & 1.748 & -2.496 & -1.105 & -1.683\end{array}\right]$

$\mathrm{S}$ - matrix of coefficients:

$\left[\begin{array}{cccccccc}0.137 & 0 & 0 & 0 & 0 & 0 & 0 & 0 \\ 0 & 0.055 & 0 & 0 & 0 & 0 & 0 & 0 \\ 0 & 0 & 2.96 & 0 & 0 & 0 & 0 & 0 \\ 0 & 0 & 0 & 0.017 & 0 & 0 & 0 & 0 \\ 0 & 0 & 0 & 0 & 5.78 & 0 & 0 & 0 \\ 0 & 0 & 0 & 0 & 0 & 0.333 & 0 & 0 \\ 0 & 0 & 0 & 0 & 0 & 0 & 0.714 & 0 \\ 0 & 0 & 0 & 0 & 0 & 0 & 0 & 0.135\end{array}\right]$

B - vector of thershold values:

$$
\left[\begin{array}{lllll}
-2.992 & 1.744 & 4.819 & -1.105 & -4.194
\end{array}\right]
$$

C - column vector of weighing values:

$$
\left[\begin{array}{lllll}
1.238 & -0.486 & -1.266 & -1.011 & -2.870
\end{array}\right]
$$

$\mathrm{P} \quad-$ vector of displacement values:

$$
\left[\begin{array}{lllllll}
-0.592 & -0.892 & -0.368 & -0.792 & -0.499 & -1.765 & -0.286
\end{array}\right]
$$

- of maximum significant amplitudes of vertical accelerations:

$$
a_{v \max }=H_{S} \cdot \frac{\frac{1}{1+e^{-[(X \times S+P) \times A-B]}} \times C+0.45}{0.0905}
$$

where: $\mathrm{a}_{\mathrm{vmax}}-\underset{\text { maximum significant amplitudes of vertical }}{\text { accelerations }\left[\mathrm{m} / \mathrm{s}^{2}\right]}$

$\mathrm{X}-$ vector of values of the design parameters:

$$
\mathrm{X}=\left[\mathrm{CBF}, \mathrm{F}_{\mathrm{w}}, \mathrm{XF}, \mathrm{V}, \mathrm{CB}(\mathrm{V})\right]
$$

where:

$\mathrm{CB}(\mathrm{V})$ - underwater hull prismatic coeffcient,

A - matrix of weighing values:

$\left[\begin{array}{cccc}1.645 & 0.065 & 0.000 & -0.048 \\ -0.919 & -1.420 & -3.301 & -7.784 \\ -0.571 & 1.225 & 1.681 & 0.724 \\ 0.145 & -0.542 & 0.196 & -0.328 \\ -7.237 & -3.253 & 0.918 & 0.395\end{array}\right]$

$\mathrm{S} \quad-$ matrix of coefficients:

[

B - vector of threshold values:

$\left[\begin{array}{llll}3.122 & 0.866 & 1.659 & 2.181\end{array}\right]$

C - column vector of weighing values:

$\left[\begin{array}{llll}-2.722 & 2.138 & 1.506 & 4.617\end{array}\right]$

P - vector of displacement values:

$$
\left[\begin{array}{lllll}
-2.250 & -0.196 & -0.447 & -0.238 & -4.407
\end{array}\right]
$$

Structures of the above described networks are presented in Fig. 8, and their statistical parameters - in Tab. 4. The parameters given in Tab. 4 concern the data from the set used to learn (amounting to $50 \%$ of cases) and that to validate the network (25\% of cases), as well as the testing set $(25 \%$ of cases). The cases from the learning set were used to learn the network, and the cases from the validating set were used for tracking network operation errors, identifying the best network and stopping the learning process in the case of occurrence of over-learning symptoms. The testing set is not used at all during the learning process and is intended only for the independent determining of the network's effectiveness on completion of its designing process.

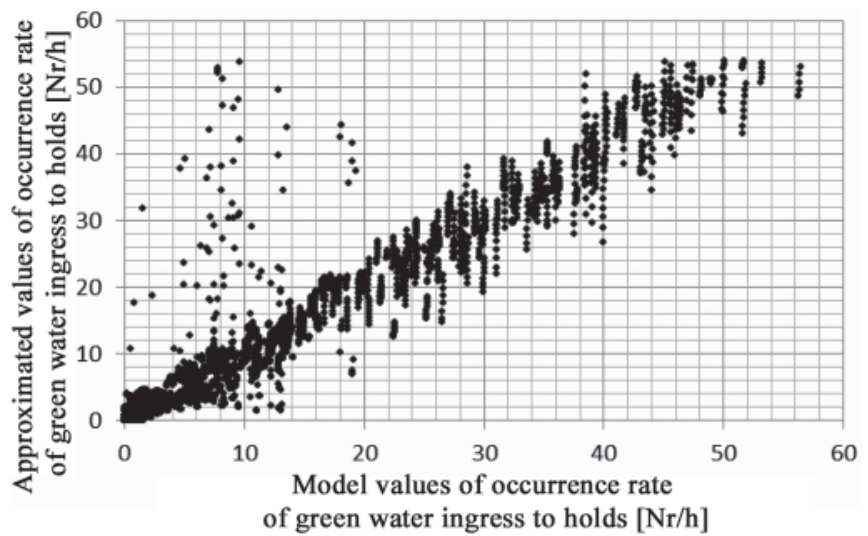

Fig. 5. Comparison of approximations of maximum occurrence rate of green water ingress to holds with their model values

In Fig. 5 through 7 are presented comparisons of approximated values with model ones for all the data contained 
Tab. 4. Statistical parameters of the elaborated artificial neural networks, where: $\boldsymbol{U}$ - learning set (50\% of cases), $\boldsymbol{W}-$ validating set (25\% of cases),

$\boldsymbol{T}$-testing set (25\% of cases), $n_{\text {stmax }}$ - maximum hourly occurrence rate of bow slamming, $\boldsymbol{T}_{n \text { n }}$ - characteristic wave period for which maximum occurrence rates of green water entering the deck fore take place, $\boldsymbol{T}_{n s}$ - characteristic wave period for which maximum occurrence rates of slamming take place

\begin{tabular}{|c|c|c|c|c|c|c|c|c|c|}
\hline & \multicolumn{3}{|c|}{$\mathbf{n}_{\mathrm{zmax}}$} & \multicolumn{3}{|c|}{$\mathbf{a}_{\text {tmax }}$} & \multicolumn{3}{|c|}{$\mathbf{a}_{\mathrm{vmax}}$} \\
\cline { 2 - 10 } & $\begin{array}{c}\mathbf{U} \\
{[\mathbf{N r} / \mathbf{h}]}\end{array}$ & $\begin{array}{c}\mathbf{W} \\
{[\mathbf{N r} / \mathbf{h}]}\end{array}$ & $\begin{array}{c}\mathbf{T} \\
{[\mathbf{N r} / \mathbf{h}]}\end{array}$ & $\begin{array}{c}\mathbf{U} \\
{\left[\mathbf{m} / \mathbf{s}^{2}\right]}\end{array}$ & $\begin{array}{c}\mathbf{W} \\
{\left[\mathbf{m} / \mathbf{s}^{2}\right]}\end{array}$ & $\begin{array}{c}\mathbf{T} \\
{\left[\mathbf{m} / \mathbf{s}^{2}\right]}\end{array}$ & $\begin{array}{c}\mathbf{U} \\
{\left[\mathbf{m} / \mathbf{s}^{2}\right]}\end{array}$ & $\begin{array}{c}\mathbf{W} \\
{\left[\mathbf{m} / \mathbf{s}^{2}\right]}\end{array}$ & $\begin{array}{c}\mathbf{T} \\
{\left[\mathbf{m} / \mathbf{s}^{2}\right]}\end{array}$ \\
\hline Standard deviation & 8.86 & 8.60 & 8.95 & 1.428 & 1.317 & 1.456 & 0.491 & 0.512 & 0.498 \\
\hline Mean absolute error & 0.94 & 0.93 & 0.96 & 0 & 0.010 & -0.004 & -0.001 & 0 & -0.001 \\
\hline Correlat-ion & 0.96 & 0.96 & 0.95 & 0.999 & 0.998 & 0.999 & 0.998 & 0.998 & 0.998 \\
\hline
\end{tabular}

in the learning, testing and validating sets. As results from the comparisons in question, the elaborated approximations are characteristic of both simple structure and high accuracy.

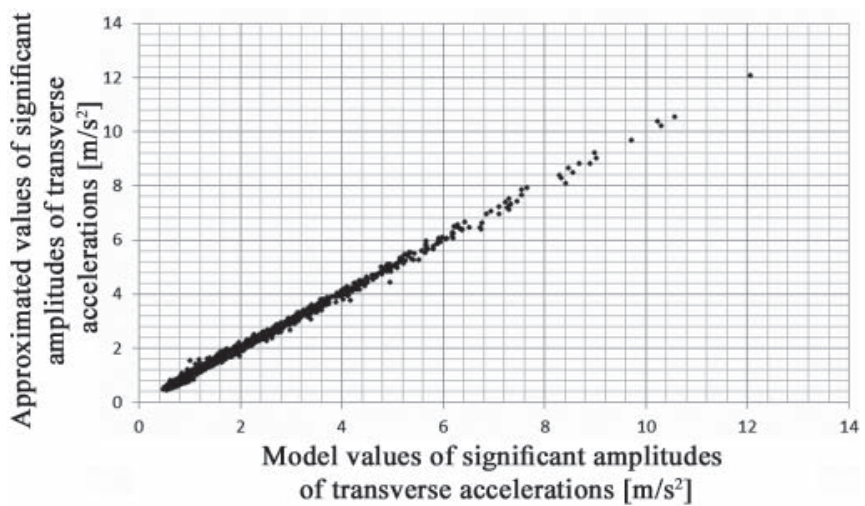

Fig. 6. Comparison of approximations of significant amplitudes of transverse accelerations with their model values

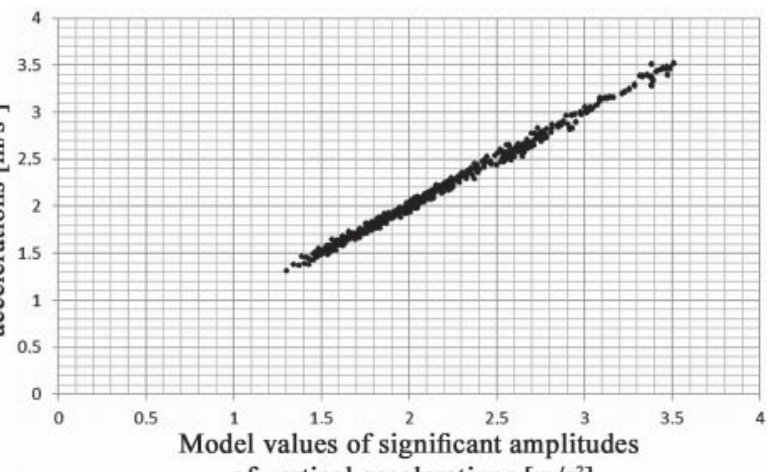
of vertical accelerations $\left[\mathrm{m} / \mathrm{s}^{2}\right]$

Fig. 7. Comparison of approximations of significant amplitudes of vertical accelerations with their model values a)

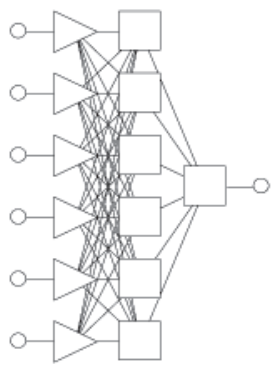

b)

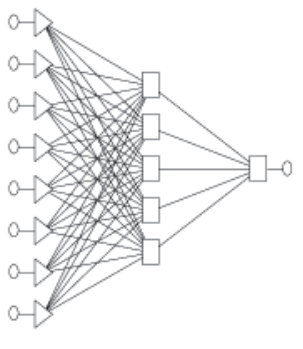

c)

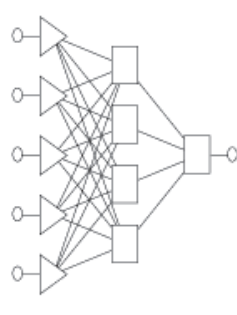

Fig. 8. Structures of the artificial neural networks which approximate: a) maximum occurrence rate of green water ingress to holds, b) maximum significant amplitudes of transverse accelerations, c) maximum significant amplitudes of vertical accelerations

\section{SUMMARY}

The elaborated approximations of seakeeping qualities of open-top containerships may be used in the preliminary design phase for:

- determination of crucial design parameters affecting green water ingress to holds, transverse and vertical accelerations,

- approximation of:

- maximum occurrence rate of green water ingress to holds in the point A (acc. Fig. 4),

- maximum significant amplitudes of transverse and vertical accelerations in the point B of the hold,

- assessment of ship seakeeping qualities,

- optimization of ship design parameters from the point of view of the assumed seakeeping qualities.

The elaborated approximations described by Eq. (1) through (3) appeared very accurate. In the research was assumed a wide range of values of ship design parameters as well as a limited range of the parameters which describe ship operational conditions according to ship operational scenario. Application of linear methods to predicting the assumed seakeeping qualities for the ships of the considered group has not led to reaching sufficient approximation accuracy. Hence the theory of artificial neural networks has been applied to this end.

The elaborated approximation functions are applicable to modelling seakeeping qualities in the following range:

- the assumed ranges of hull geometric parameters on the basis of which model values of seakeeping qualities were calculated, the following in particular:

- the ship length b. p. / breadth ratio $\mathrm{L}_{\mathrm{pp}} / \mathrm{B}$ : from $5.3 \div 8.3$

- the ship breadth/draught ratio B/d: from $2.32 \div 4.72$,

- the ship depth/draught ratio $\mathrm{H} / \mathrm{d}$ : from $1.3 \div 3.33$,

- the freeboard height $\mathrm{Fb}=\mathrm{H}-\mathrm{d}$ : from $3 \div 10 \mathrm{~m}$,

- the underwater hull block coefficient $\mathrm{CB}$ : from $0.54 \div 0.70$,

- the midship section coefficient CM: from $0.92 \div 0.98$,

- the waterplane coeffcient CWL: from $0.67 \div 0.85$,

- the blok coefficient of underwater hull fore part, CBF: from $0.45 \div 0.65$,

- the distance from waterplane geometric centre to aft perpendicular, XF: from $41.6 \div 134.65 \mathrm{~m}$

- the ship length b.p. $\mathrm{L}_{\mathrm{pp}}$ : from $100 \div 280 \mathrm{~m}$,

- the ship breadth B: from $16 \div 37.67 \mathrm{~m}$,

- the ship draught d: from $4.3 \div 12.81 \mathrm{~m}$,

- the underwater hull volume V: from $3780 \div$ $91000 \mathrm{~m}^{3}$

- the waterplane area Fw: from $1072 \div 9000 \mathrm{~m}^{2}$, 
- the assumed wave conditions:

- the significant wave height Hs: from $0 \div 8.5 \mathrm{~m}$,

- the JONSWAP wave spectrum,

- the characteristic wave period $\mathrm{T}_{1}$ : from $2 \div 20 \mathrm{~s}$,

- The assumed ship motion parameters:

- the ship speed $\mathrm{V}=10 \mathrm{~m} / \mathrm{s}$,

- the wave encounter angles:

- $\beta=120^{\circ}$ for green water ingress to holds,

- $\beta=120^{\circ}$ for transverse accelerations,

- $\beta=90^{\circ}$ for vertical accelerations.

\section{BIBLIOGRAPHY}

1. Baranowski A., Bech T., Lech R.: Seakeeping qualities of opentop containerships. Polish Maritime Research,vol. 4, No. 4(14), 1997

2. BOMEL Limited: Analysis of green water susceptibility of FPSO/FSU's on the UKCS, Offshore Technology Report 2001/ 005, 2001

3. Buchner B., Garcia J.L.C.: Design aspects of green water loading on FPSOs. The $22^{\text {nd }}$ International Conference on Offshore Mechanics \& Arctic Engineering Cancun, Mexico $8 \div$ 13 June, 2003
4. Cepowski T.: Modelling of green water ingress to holds of an open-top containership in its preliminary design phase. Polish Maritime Research, Vol. 16, No 1(59), 2009

5. Chądzynski W.: Open top container vessel design problems. Marine Technology Transactions, Technika Morska, Vol. 9, 1998

6. International Maritime Organization: Interim Guidelines for Open-Top Container Ships. MSC/Circ.608/Rev.1. London, 1994

7. Report on the investigation of the collapse of cargo containers on Annabelle, Baltic Sea, 2007

8. Watanabe, I., Ueno, M. and Sawada, H.: Effect of Bow Flare Shape to the Wave Loads of a Container Ship, JSNA Japan, Vol. 166,1989

9. Wiśnicki B., Vademecum of containerization. Forming the container load unit (in Polish). LINK publishers, 2006.

CONTACT WITH THE AUTHOR

Tomasz Cepowski, Assoc. Prof.

Institute of Marine Navigation,

Maritime University of Szczecin

Wały Chrobrego $1 / 2$

70-500 Szczecin, POLAND

e-mail: cepowski@am.szczecin.pl 